Scientiæ studia, São Paulo, v. 9, n. 3, p. 669-75, 2011

\title{
O inovacionismo em questão
}

\author{
Marcos Barbosa de Oliveira
}

O documento publicado a seguir - A ciência e a agenda empresarial: as consequências nefastas da influência comercial sobre a ciência e a tecnologia - consiste na tradução do Sumário Executivo de um relatório produzido pelo movimento Scientists for Global Responsibility (SGR), do Reino Unido, e dado a público em setembro de 2009. Na primeira parte desta apresentação, tratamos do relatório da perspectiva do Reino Unido e, mais amplamente, dos países centrais; na segunda, procuramos esclarecer seu significado para o Brasil.

O SGR foi fundado em 1992, resultando da fusão de três movimentos formados para combater o uso da ciência e da tecnologia para fins militares, visando, em particular, a eliminação das armas nucleares. ${ }^{1}$ Com sua fundação, ampliou-se o leque de questões, sendo adotado como objetivo central a mobilização contra todos os usos da ciência e da tecnologia que ameaçam a vida humana e o meio ambiente. Em 2005, uma quarta organização - a Architects and Engineers for Social Responsibility - juntou-se ao SGR, que tem atualmente mais de 1.000 membros, entre cientistas naturais e sociais, engenheiros, arquitetos e profissionais da área de informação.

A plataforma do SGR é estruturada pela tese de que a ciência faz parte dos problemas mais graves que a humanidade enfrenta na atualidade, mas faz também parte da solução. Ela é parte do problema por ser co-responsável pelo aumento do poder destrutivo dos armamentos, pelas mudanças climáticas decorrentes da emissão dos gases de efeito estufa, pelo esgotamento dos recursos naturais, pela degradação ambiental decorrente do modelo tecnológico de agricultura, pelos riscos inerentes ao uso de energia nuclear e ao desenvolvimento de tecnologias emergentes, a saber, a biotecnologia,

$1 \mathrm{O}$ site do SGR encontra-se em 〈http://www.sgr.org.uk/frontpage $\rangle$. 
a nanotecnologia e a geoengenharia. Ela é parte da solução porque são reconhecidos os incontáveis benefícios que a ciência moderna proporciona, dos quais não faz sentido abrir mão, e por conta do caráter imprescindível da contribuição que ela pode, desde que bem conduzida, prestar para a superação dos problemas que ajudou a criar.

Desde sua fundação, o SGR desenvolve uma ampla gama de atividades, incluindo estudos, publicações, conferências e campanhas. Uma das principais linhas de atuação é a que visa promover a democratização das práticas científicas e tecnológicas. A iniciativa é orientada pelo pressuposto de que apenas com base em um diálogo genuíno entre cientistas e não cientistas o objetivo pode ser atingido, o que por sua vez demanda posições de respeito mútuo, para superar os malentendidos que alimentam confrontos estéreis, bem como, por parte dos cientistas, o exercício da responsabilidade social. Tendo em vista a formação de cientistas socialmente responsáveis, o SGR publicou o livreto An ethical career in science and technology?, um guia prático para iniciantes expondo os imperativos da responsabilidade social e os obstáculos a seu exercício decorrentes das formas atuais de administração do trabalho dos pesquisadores (Parkinson \& Spedding, 2001).

O artigo Formas de autonomia da ciência, publicado neste número de Scientiae Studia, traz uma descrição e uma interpretação do relatório do SGR em pauta que pode fazer as vezes de uma apresentação do "Sumário executivo" publicado a seguir, e que nos limitaremos a resumir aqui. A interpretação é feita em termos do inovacionismo, definido como a diretriz que postula a obtenção de inovações como objetivo primordial da pesquisa científica, entendendo-se por inovação uma invenção, quando efetivamente lançada no mercado por uma empresa. O inovacionismo é explicado como um meio de promover a mercantilização da ciência, e envolve uma associação estreita, um "casamento" da ciência com o setor empresarial.

O relatório é interpretado como paradigma de um determinado tipo de questionamento que deve ser dirigido ao establishment científico partidário do inovacionismo. $\mathrm{O}$ questionamento tem por fulcro as consequências nefastas da associação da ciência com as empresas; e as características que justificam a atribuição do status de paradigma ao relatório são: o aspecto interno de sua crítica, que envolve um mínimo de pressupostos e valores inaceitáveis pelos interlocutores; a fundamentação das alegações em evidências empíricas estabelecidas de acordo com as normas do método científico; e a postura propositiva, que não se limita a expor os problemas, mas também aponta os caminhos para sua superação. Esses atributos fazem com que o questionamento traga em si o antídoto contra as acusações de obscurantismo e anticientificismo com os quais o establishment procura desqualificar os críticos.

Gabe observar, por outro lado, que o relatório não é isento de limitações. Uma delas - explicitamente reconhecida por seus autores, e bem compreensível, dada a 
quantidade de trabalho envolvida na elaboração de uma versão mais completa - é a concentração do foco no Reino Unido, com apenas algumas referências à situação dos Estados Unidos. Outra limitação, inevitável neste tipo de trabalho, é a decorrente do caráter transitório da realidade estudada, em permanente mudança, implicando a necessidade de atualizações frequentes para que a crítica não perca sua validade. $\mathrm{O}$ relatório deve, portanto, ser lido, não como uma refutação das teses inovacionistas, que se faz de uma vez por todas, mas, vale a pena enfatizar, como um paradigma, um modelo de iniciativa a ser empreendida por movimentos críticos de todos os países, empenhados em aperfeiçoar a maneira como as práticas científicas são conduzidas.

Todas as considerações acima têm como pano de fundo o Reino Unido e, mais amplamente, os países centrais. Terão as teses do relatório o mesmo significado para o Brasil? Para esboçar uma resposta a tal pergunta, partimos de um relato - muito sucinto e esquemático, dada a complexidade do fenômeno - a respeito da fortuna do inovacionismo em nosso país.

O inovacionismo, como se lê em Formas de autonomia da ciência, teve sua semente plantada por Christopher Freeman em meados dos anos 70 do século passado, desenvolveu-se com mais vigor a partir da criação, cerca de uma década mais tarde, do conceito de "sistema nacional de inovação", cuja paternidade também é atribuída a Freeman, e, nos anos 9o, já se encontrava bem estabelecido nos países centrais. Com certo atraso, como sói acontecer nesses casos de importações de ideias originárias do centro, o inovacionismo aportou no Brasil por volta do ano 2000, porém desenvolveu-se muito rapidamente.

No plano jurídico, os principais marcos desse processo foram: a criação dos primeiros fundos setoriais, em 1999; a realização da $2^{\text {a }}$ Conferência Nacional de Ciência, Tecnologia e Inovação (CNCTI), em 2001; ${ }^{2}$ a Lei de Inovação, promulgada em 2004; a chamada Lei do Bem, de 2005; e o Plano de Ação em Ciência, Tecnologia e Inovação para o Desenvolvimento Nacional (PACTI), instituído em 2007. No plano econômico, as agências de fomento e órgãos afins dos governos federal e estaduais adotaram inúmeros programas de apoio à pesquisa visando a inovação, e envolvendo o setor empresarial, na forma de convênios, empréstimos subsidiados, financiamentos a fundo per-

2 A conferência realizada em 1985, a primeira da série, só retrospectivamente foi considerada como tal. Seu nome era apenas Conferência Nacional de Ciência, Tecnologia (sem “inovação"). A terceira e a quarta conferências ocorreram em 2005 e 2010 . 
dido, bolsas etc. ${ }^{3}$ No plano institucional, criaram-se entidades, tanto no setor público (por exemplo, as "agências de inovação" nas universidades), como no setor privado (na forma de associações empresariais, consultorias, ONGs etc.). Campanhas e concursos são promovidos com o intuito de instilar no público a "cultura da inovação", como, por exemplo, a Olimpíada USP de Inovação. ${ }^{4}$ Em janeiro de 2010 o presidente Lula sancionou a Lei n. 12.193, que designa o dia 19 de outubro como Dia Nacional da Inovação. No Livro azul, que sintetiza as principais contribuições da $4{ }^{\text {a }}$ CNCTI afirma-se, em um arroubo retórico bem expressivo do entusiasmo com o inovacionismo, que "o Brasil tem uma necessidade gigantesca, urgente, de inocular inovação em todos os poros da economia" (Ministério, 2010, p. 35).

Trata-se, enfim, de uma enorme mobilização que envolve dispêndio considerável de verbas públicas, bem como das energias intelectuais e emocionais da nação. Qual é o resultado de todo esse esforço?

Em 2010, vieram à tona dados estatísticos muito pouco auspiciosos para os adeptos do inovacionismo, para dizer o mínimo. Boa parte deles é resultado da $4^{\text {a }}$ Pesquisa de Inovação Tecnológica (PINTEG), realizada pelo Instituto Brasileiro de Geografia e Estatística (IBGE, 2010), com apoio da Financiadora de Estudos e Projectos (FINEP). 5 O Ministério de Ciência e Tecnologia (MCT) também compila, a partir de várias fontes, uma série de estatísticas sobre as atividades científicas e tecnológicas, e as divulga em seu site, na seção de indicadores, atualizada com frequência. Uma lista não exaustiva dos resultados mais claramente desfavoráveis inclui os seguintes:

(1) a proporção entre as parcelas dos recursos investidos em ciência e tecnologia pelo setor público e pelo setor privado constitui um indicador dos avanços do inovacionismo: quanto maior a parte do setor privado, maior o

30 governo federal, através de vários órgãos, mantém entre outros o Programa de Subvenção Econômica à Inovação, o Programa de Apoio à Pesquisa em Empresas (Pappe), o Programa Primeira Empresa Inovadora (Prime), e o Programa RHAE-Pesquisador na Empresa. Entre as agências estaduais, destaca-se a Fundação de Amparo à Pesquisa do Estado de São Paulo (FAPESP), com o Programa Pesquisa Inovativa em Pequenas Empresas (PIPE), o Programa Pesquisa em Parceria para Inovação Tecnológica (PITE), e o Programa de Apoio à Propriedade Intelectual (PAPI). ${ }_{4}$ É curioso observar, e isto vale também para os países centrais, que no discurso inovacionista, especialmente aquele mobilizado em campanhas dirigidas ao grande público, o valor positivo da inovação é com frequência simplesmente pressuposto, como um truísmo que dispensa qualquer forma de demonstração; e daí, é um passo para ver nas inovações a cura de todos os males. Tal concepção deixa sem resposta as seguintes perguntas: se o valor da inovação é assim tão autoevidente, por que o inovacionismo, e o próprio conceito de inovação, surgiram quando surgiram, na década de 7o do século passado, não antes ou depois? Como se explica essa iluminação que a humanidade teria tido nesse momento histórico, essa descoberta do óbvio? Será a coincidência cronológica com a ascensão do neoliberalismo mera coincidência?

5 Os dados estatísticos levantados pela 4 a PINTEC e publicados em 2010 referem-se, alguns, ao período de 2005 a 2008, outros, ao ano de 2008. A mesma defasagem ocorreu nas edições anteriores, publicadas em 2002, 2005 e 2007 . 
avanço. Na média dos países da Organização para a Cooperação e o Desenvolvimento Econômico (OCDE), os recursos privados giram em torno de 69\% do total; no Brasil, 47\%. A porcentagem no caso do Brasil tem se mantido mais ou menos estável, com uma ligeira queda no último ano para o qual os dados estão disponíveis, de 47,74\% em 2008 para 45,25\% em 2009. Em proporção ao PIB, o investimento do setor público no Brasil é apenas $15 \%$ menor que a média da $\operatorname{OCDE}(0,59 \%$ e o,67\%, respectivamente); o das empresas não chega a $1 / 3$ ( $0,4,8 \%$ e 1,4.9\%, respectivamente);

(2) a taxa de inovação, definida como a porcentagem de empresas que implementaram inovações, subiu de 34,4\% no período 2003-2005 (3 $3^{\mathrm{a}}$ PINTEC) para 38,6\% em 2006-2008 (4 ${ }^{\text {a }}$ PINTEC). Entretanto, uma parte substancial do que se conta como inovação implementada corresponde à aquisição de máquinas, equipamentos, softwares etc., não à criação propriamente dita de inovações, fruto de atividades internas de P\&D. Quando se consideram apenas as empresas que realizam atividades internas de P\&D, a porcentagem - que pode ser entendida como a taxa real de inovação - não apenas é muito menor, mas caiu bastante, de 6,4\% em 2005 para $4,4 \%$ em 2008;

(3) o número de pessoas trabalhando em atividades internas de pesquisa nas empresas, que vinha subindo desde 2000, sofreu um retrocesso, caindo de 49.354 em 2005 para 45.34,2 em 2008. Quando se consideram apenas os pesquisadores com pós-graduação, a porcentagem de queda é praticamente a mesma, mas os números são bem menores: 11.283 em 2005 e 10.292 em 2008;

(4) o número de patentes de utilidade obtidas junto ao United States Patent and Trademark Office (USPTO), depois de um pico de 130 em 2003, caiu para 98 na média dos três últimos anos para os quais os dados já foram apurados (2007, 2008, 2009). Nesse mesmo período, a média da Coreia do Sul-um país frequentemente usado como termo de comparação com o nosso - foi $7 \cdot 5^{3} 5$. O número de patentes por mil pesquisadores no Brasil é 1,8; na Coreia 45, ou seja, 25 vezes maior.

Alguns desses números foram citados e comentados na seção sobre o Brasil do UNESCO Science Report 2010, assinada por representantes brasileiros da FAPESP e da Universidade de São Paulo (Unesco, 2010). O relatório foi lançado no dia 10 de novembro, os resultados da 4 a PINTEG um pouco antes, em 29 de outubro. A repercussão na grande imprensa veio logo a seguir, em editoriais, entrevistas e outras matérias com títulos tais como "Brasil não transforma ciência em lucro" (Mioto, 2010), "Inovação estagnada" (Editorial, 2010), e "Ciência no setor privado ainda frustra" (Cruz, 2010). 
O insucesso, até o presente, da mobilização inovacionista é água para o moinho de críticos, como Renato Dagnino, defensores da tese de que a inapetência dos empresários pela inovação não resulta de um déficit cultural, como se costuma alegar, mas sim da própria racionalidade maximizadora dos lucros, no contexto de uma economia periférica como a brasileira (cf. Dagnino, 2010b). Uma evidência a favor dessa tese encontra-se nas respostas dadas pelas empresas às perguntas sobre os "problemas e

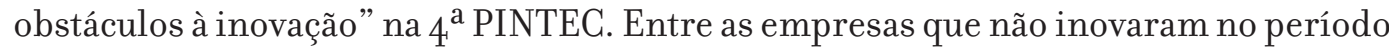
pesquisado, $55,8 \%$ apontaram as "condições de mercado" como razão para isso. E entre as 28,3\% que alegaram "outros fatores", $75,3 \%$ atribuíram grau de importância alto ou médio para o fator "elevados custos da inovação", e 68,1\% para o fator "riscos econômicos excessivos". Sendo os custos e riscos avaliados em comparação com o retorno previsto, pode-se concluir, simplificando, e expressando em linguagem corriqueira, que os empresários no Brasil não investem em pesquisas visando inovações porque esse não é um bom negócio.

Tal conclusão sustenta a crítica segundo a qual, salvo mudanças profundas nas estrutura, dimensões e inserção da economia brasileira na economia mundial, a meta inovacionista de integrar a pesquisa acadêmica e o setor empresarial, como meio de direcionar a pesquisa acadêmica para a obtenção de inovações, é irrealizável.

Voltando agora ao relatório do SGR, pode-se dizer, também simplificadamente, que ele implica uma outra crítica ao inovacionismo, a saber, a de que a própria meta deixa a desejar, isto é, pior que não-compensadora (no sentido de que o retorno não compensa o investimento), é indesejável (no sentido de que as consequências nefastas superam os benefícios de sua realização). É uma situação a ser evitada, não buscada.

Se a meta é indesejável, pode-se pensar que é uma boa coisa o fato de ser irrealizável. Seria, se não fosse pelo enorme gasto de recursos com a mobilização inovacionista, não apenas de verbas públicas, mas também das energias, da dedicação das pessoas nela empenhadas, a grande maioria sem dúvida imbuída das melhores intenções.

Mas qual é a alternativa? O grupo mais avançado nesse terreno é o liderado por Dagnino, que vem, já há certo tempo, desenvolvendo a alternativa da tecnologia social, isto é, a re-orientação da pesquisa científica e tecnológica da obtenção de inovações para a pesquisa, voltada primordialmente para a inclusão social, como componente de um sistema de economia solidária (cf. Dagnino, 2010a). Uma exposição mais extensa e uma defesa da tecnologia social não cabem aqui; ela é mencionada apenas para sugerir que, pelo menos nesse campo, não vale a máxima TINA, de Margareth Thatcher, there is no alternative.

A partir dessas considerações pode-se dizer, respondendo à pergunta posta como tema para esta segunda parte da apresentação, que o significado do relatório para os países centrais tem um componente de denúncia pela exposição dos efeitos pernicio- 
sos da integração academia/empresa; para o Brasil, o componente análogo tem o sentido de um alerta, um estímulo para que se empreenda uma reflexão séria a respeito do valor da inovação, da maneira como é concebida, isto é, como mercadoria e, no fundo, a respeito da eficiência do mercado como instância organizadora da pesquisa científica e tecnológica. Essa interpretação foi o motivo da proposta de publicar em Scientiae Studia o documento que o leitor encontra a seguir.@

\section{Marcos Barbosa de Oliveira}

Professor Associado da Faculdade de Educação, Universidade de São Paulo.

Pesquisador Principal do Projeto Temático Fapesp o $/ 5^{386} 7^{-0}$,

Departamento de Filosofia, Universidade de São Paulo, Brasil.

Marcos Barbosa de Oliveira

\section{REFERÊNGIAS BIBLIOGRÁFIGAS}

CRuz, B. Ciência no setor privado ainda frusta. Entrevista concedida a Alexandre Gonçalves. O Estado de S. Paulo, $19 /$ nov./2010.

Dagnino, R. (Ed.). Tecnologia social: ferramenta para construir outra sociedade. 2 ed. Campinas: Komedi, 2010a.

. Por que os “nossos" empresários não inovam? In: (Ed.). Estudos sociais da ciência e tecnologia \& política de ciência e tecnologia: alternativas para uma nova América Latina. Campina Grande: EDUEPB, 2010 b. p. $47^{-68 .}$

EDitorial. Inovação estagnada. Folha de S. Paulo, 12/nov./2010.

IBGE. Pesquisa de inovação tecnológica 2008 (4a PINTEC). Rio de Janeiro: IBGE, 2010.

Ministério da Ciência e Tecnologia. Livro Azul: $4^{a}$ Conferência Nacional de Ciência, Tecnologia e Inovação para o Desenvolvimento Sustentável. Brasília: Ministério da Ciência e Tecnologia/Centro de Gestão e Estudos Estratégicos, 2010.

Мıото, R. Brasil não transforma ciência em lucro. Folha de S. Paulo, 10/nov./2010.

Parkinson, S. \& Spedding, V. (Ed.). An ethical career in science and technology? Folkestone: Scientists For Global Responsibility, 2001. Disponível em: <http://www.sgr.org.uk/publications /ethical-careerscience-and-technology>. Acesso em: 13/3/2011.

Unesco. Unesco science report 2010: the current status of science around the world. Paris: Unesco, 2010.

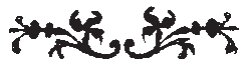

